\title{
Characterization of Three-Way Translocation [t(4;9;22)(p16;q34;q11.2)] in Chronic Myeloid Leukemia
}

\author{
Salil Vaniawala, Pratik Chavda, Ganesh Jori, Keur Patil, Pankaj Gadhia* \\ Molecular Cytogenetic Unit, S. N. Gene Laboratory and Research Centre, Surat, India \\ Email address: \\ pankajkgadhia@gmail.com (P. Gadhia)
}

\section{To cite this article:}

Salil Vaniawala, Pratik Chavda, Ganesh Jori, Keur Patil, Pankaj Gadhia. Characterization of Three-Way Translocation $[\mathrm{t}(4 ; 9 ; 22)(\mathrm{p} 16 ; \mathrm{q} 34 ; \mathrm{q} 11.2)]$ in Chronic Myeloid Leukemia. International Journal of Clinical and Experimental Medical Sciences. Vol. 1, No. 2, 2015, pp. 30-34. doi: 10.11648/j.ijcems.20150102.16

\begin{abstract}
The Philadelphia (Ph) chromosome, consisting of the $\mathrm{t}(9 ; 22)(\mathrm{q} 34 ; \mathrm{q} 11.2)$ is observed in $90 \%$ with chronic myeloid leukemia $(\mathrm{CML})$, while variant translocations are observed in 5 to $10 \%$. In variant translocations, three way translocations are rare. We report two cases of three way translocation involving chromosomes 4, 9 and 22. Bone-marrow was subjected to conventional cytogenetic and fluorescence in situ hybridization (FISH) and three way translocation was identified as 46,XX,t(4;9;22)(p16;q34;q11.2). Although other chromosomes are frequently involved in three-way translocation, chromosome 4 is very rare event. So far five cases have been reported in the literature with translocation involving $4 \mathrm{p} 16$. We present a six case of chronic myeloid leukemia having 4 p16 breakpoints whose clinical interpretation is still unclear.
\end{abstract}

Keywords: Chronic Myeloid Leukemia, t(9;22), Three-Way Translocation Variant, FISH, Cytogenetic

\section{Introduction}

Chronic myeloid leukemia (CML) is a clonal myeloproliferative disorder arising from neoplastic transformations in a pluripotent cell. The hallmark of CML is presence of Philadelphia chromosome $(\mathrm{Ph})$, resulting from the $t(9 ; 22)(q 34 ; q 11.2)[1]$. The crucial consequence of this translocation is the formation of a novel and chimeric $\mathrm{BCR} / \mathrm{ABL}$ (break point cluster region-Abelson) gene in the breakpoint region of the derivative chromosome [2]. The $\mathrm{BCR} / \mathrm{ABL}$ fusion gene generated encodes on oncogenic protein tyrosine kinase which causes the genesis of CML by activating multiple signaling pathways that are involved in cell cycle, adhesion and apoptosis [3].

In $70-85 \%$ of $\mathrm{CML}$ cases having $\mathrm{t}(9 ; 22)$ Philadelphia positive, however, in 5 to $10 \%$ of CML cases, there is a variant $\mathrm{Ph}$ translocation with generally third chromosome involved with chromosome 9 and 22 [4]. The segment from third chromosome is usually translocated to band $9 \mathrm{q} 34$ whereas the $22 \mathrm{q} 11 \rightarrow$ qter segment (including the 3' BCR region) moves to breakpoint of third chromosome [5].

The formation of the variant $\mathrm{Ph}$ translocation is controversial topic. A wide array of additional chromosome involved in translocation with the $\mathrm{t}(9 ; 22)$ has been described in CML [6]. With regard to involvement of chromosome 4 that is rare, and only five previously reported cases showed a breakpoint at $4 p 16$ [7]. In the present study we report the clinical, cytogenetic and FISH findings of two patients with complex translocation involving chromosome 4, 9, 22 at breakpoint 4p16.

\section{Materials and Methods}

The present study included patients from March, 2014 to February, 2015. After taking informed consent from the patients, we examined bone-marrow samples.

Of 732 cases, of which $378(51.6 \%)$ were turned out as confirmed CML. Further analysis of variant translocations revealed only two cases of $\mathrm{t}(4 ; 9 ; 22)(\mathrm{p} 16 ; \mathrm{q} 34 ; \mathrm{q} 11.2)$ threeway complex translocation.

Conventional cytogenetic (CC) analysis was performed by our laboratory on all patients. Bone-marrow (BM) samples were cultured for 24-48 hours in Marrow Max medium without mitogen and with $10 \mathrm{ug} / \mathrm{ml}$ colcemid solution. The chromosomal slides were prepared according to standard procedures. Standard Giemsa chromosome banding stain (GTG banding) (pretreatment with trypsin then Giemsa stain) was employed [8] on metaphase spread obtained. Depending upon availability, $20-25$ metaphases per sample were analyzed. The karyotyped description followed [9] International System for Human Cytogenetic Nomenclature (ISCN) 2009 [9] recommendations. 
Fluorescence In situ Hybridization (FISH) analysis was performed on prepared slides of fixed BM cells using $\mathrm{BCR} / \mathrm{ABL}$ dual colour, dual, fusion kit (Vysis, Germany). Fluorescent signals were visualized under Axiomager Z2, Carl-Zeiss microscope.

\section{Results}

Conventional cytogenetic (CC) analysis of 732 patients (from March, 2014 to February, 2015) showed 378 cases with classical $\mathrm{t}(9 ; 22)(\mathrm{q} 34 ; \mathrm{q} 11,2)$ and rest 354 cases showed normal karyotype. Interestingly 2 patients had a variant $\mathrm{Ph}$ chromosome translocation.

Case 1:

The case number 1 was a 34-year old woman. Her blood analysis showed total white blood cell count (WBC) as $214 \mathrm{X}$ $10^{9} \mathrm{~g} / \mathrm{L}$, platelets were $606 \times 10^{9} / \mathrm{L}$, hemoglobin content was $11.3 \mathrm{~g} / \mathrm{dl}, 33 \%$ lymphocytes and $4 \%$ monocytes. She had $25 \%$ blast cells.

Cytogenetic study from bone-marrow revealed complex translocation having chromosome 46, XX, t(4;9;22) (p16;q34;q11.2) (Fig. 1).
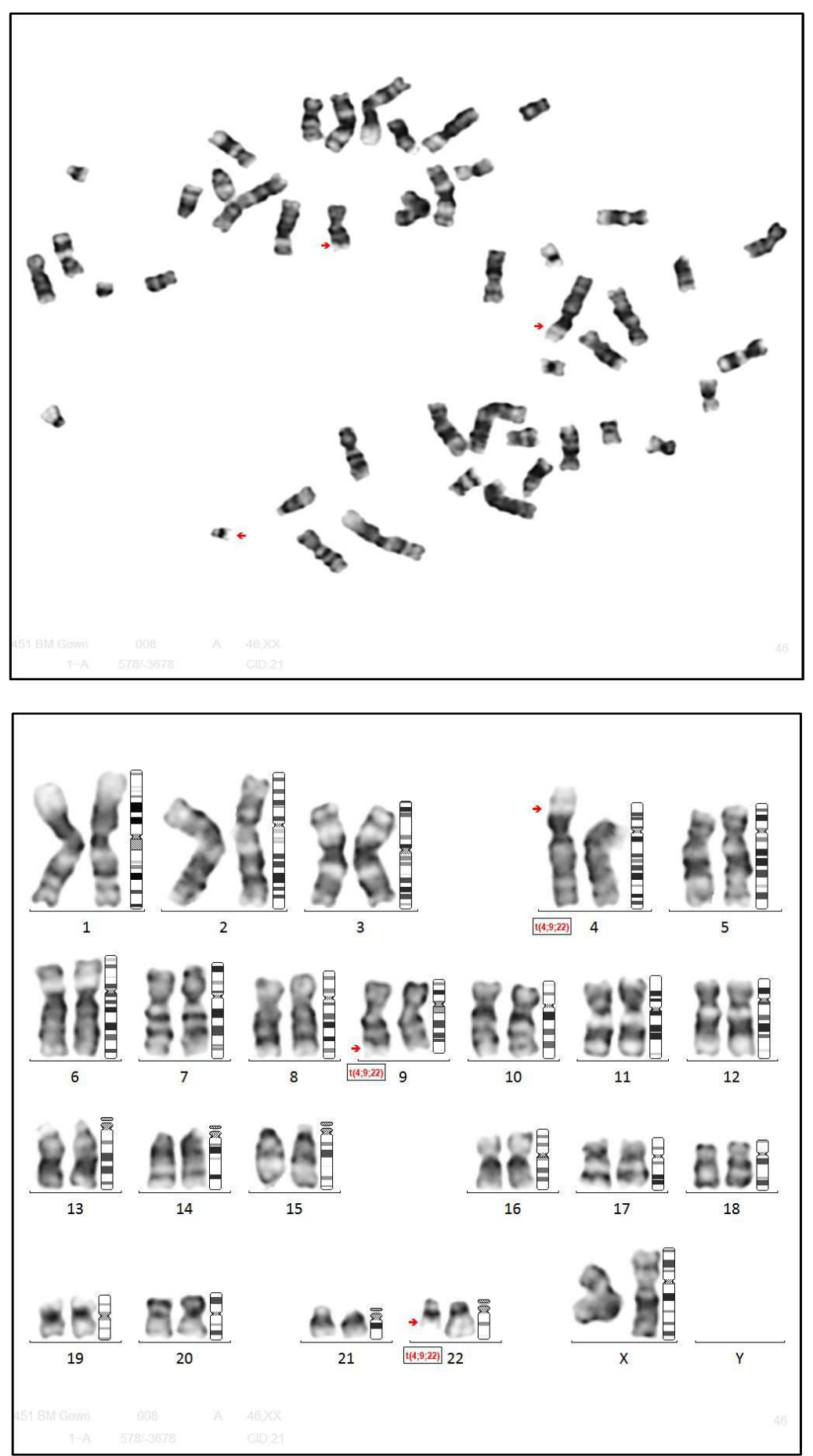

Figure 1. Karyotype of a Female with Chronic Myeloid Leukemia with Three-Way Translocation, 46,XX,t(4;9;22)(p16;q34;q11.2). 
Case 2:

The second case was a 35-year old women showing WBC count as $148 \times 10^{9} \mathrm{~g} / \mathrm{L}$. Her differential count showed 43\% lymphocytes, 6\% monocytes, platelets count was $535 \mathrm{X}$
$10^{9} / \mathrm{L}$ and hemoglobin content was $12.3 \mathrm{~g} / \mathrm{dl}$. She had $65 \%$ blast cells. The cytogenetic study revealed variant translocation having 46, XX, t $(4 ; 9 ; 22)$ (p16;q34;q11.2) (Fig. 2).
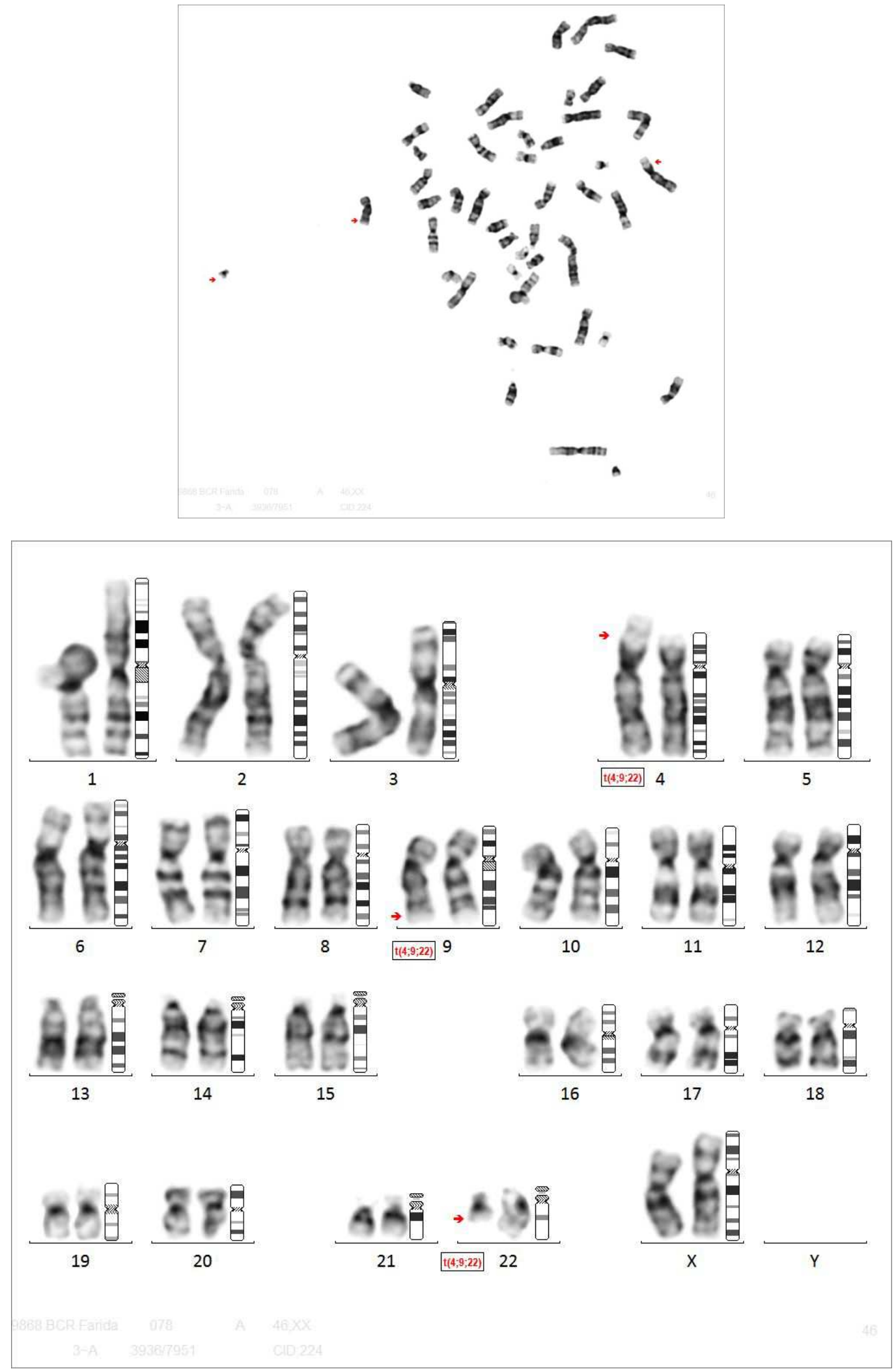

Figure 2. Karyotype of a Female with Chronic Myeloid Leukemia with Three-Way Translocation, 46,XX,t(4; 9;22)(p16;q34;q11.2). 


\section{Discussion}

Most CML patients show the Philadelphia (Ph) chromosome arising from reciprocal $\mathrm{t}(9 ; 22)$, but 5 to $10 \%$ present variants of this translocation involving different breakpoints besides 9q34 and 22q11.2 [10]. The formation of variant $\mathrm{Ph}$ translocation is a controversial topic and recognized for more than 25 years. The clinical course and influence of these variants on long term outcome are not well understood.

In the present study, we analyzed 732 cases of clinically suspected CML, of which 378 were confirmed CML with classical translocation of $\mathrm{t}(9 ; 22)$ and Philadelphia positive. Among 378 confirmed cases of CML, we found two cases of three-way translocation involving chromosome 4 and breakpoint band p16. However, involvement of chromosome 4 is rare, and previous only five cases showed a break at 4 p16 (Table1) [11-15].

Table 1. CML Patients Karyotyped Reported in Literature for t(4;9;22) with 4 p16 locus.

\begin{tabular}{lllll}
\hline Case & Karyotype & Locus & Clinical evaluation & Ref.No \\
\hline 1 & $46, \mathrm{XY}, \mathrm{t}(4 ; 9 ; 22)(\mathrm{p} 16 ; \mathrm{q} 34 ; \mathrm{q} 11.2)$ & $4 \mathrm{p} 16$ & CML: patients entered BC, additional structural Changes were seen & 11 \\
2 & $46, \mathrm{XX}, \mathrm{t}(4 ; 9 ; 22)(\mathrm{p} 16 ; \mathrm{q} 34 ; \mathrm{q} 11.2)$ & $4 \mathrm{p} 16$ & CML: Karyotyped reported when she was in CP & 12 \\
3 & $46, \mathrm{XY}, \mathrm{t}(4 ; 9 ; 22)(\mathrm{p} 16 ; \mathrm{q} 34 ; \mathrm{q} 11.2)$ & $4 \mathrm{p} 16$ & Karyotyped reported in CP & 13 \\
4 & $46, \mathrm{XY}, \mathrm{t}(4 ; 9 ; 22)(\mathrm{p} 16 ; \mathrm{q} 34 ; \mathrm{q} 11.2)$ & $4 \mathrm{p} 16$ & Karyotyped reported with BC & 14 \\
5 & $46, \mathrm{XX}, \mathrm{t}(4 ; 9 ; 22)(\mathrm{p} 16 ; \mathrm{q} 34 ; \mathrm{q} 11.2)$ & $4 \mathrm{p} 16$ & Karyotyped reported with CP & 15 \\
6 & $46, \mathrm{XX}, \mathrm{t}(4 ; 9 ; 22)(\mathrm{p} 16 ; \mathrm{q} 34 ; \mathrm{q} 11.2)$ & $4 \mathrm{p} 16$ & Karyotyped reported with CP & Present case \\
7 & $46, \mathrm{XX}, \mathrm{t}(4 ; 9 ; 22)(\mathrm{p} 16 ; \mathrm{q} 34 ; \mathrm{q} 11.2)$ & $4 \mathrm{p} 16$ & Karyotyped reported with BC $(65 \%)$ & Present case \\
\hline
\end{tabular}

BC: Blast Crisis, CP: Chronic Phase

As such masked translocations are difficult to visualize with routine cytogenetics. Few studies suggested that patients with masked and variant $\mathrm{Ph}$ translocations have adverse prognosis $[16,17]$, but others have suggested no prognostic effect [18, 19]. It is known that variant $\mathrm{Ph}$ breakpoints usually occur in the G-light bands within the cytosine (C) and guanine $(\mathrm{G})$ richest regions of the genome.

It is well established that breakpoint $4 p 16$ is rare in $\mathrm{CML}$ variant and as per Mitelman database [7] only five cases have been reported. In the present study, we reported 2 female cases from Western India. Case number 1 was reported to us with chronic phase and case number 2 with blast phase, both showed three-way translocation and chromosome complement of $46, \mathrm{XX}, \mathrm{t}(4 ; 9 ; 22)(\mathrm{p} 16 ; \mathrm{q} 34 ; \mathrm{q} 11.2) \quad$ with conventional cytogenetics. While D-FISH results indicated that three way translocation was one step mechanism where 1 fusion, 2 green and 2 orange $(1 \mathrm{~F}, 2 \mathrm{G}, 2 \mathrm{O})$ signals were recorded (Figure 3).

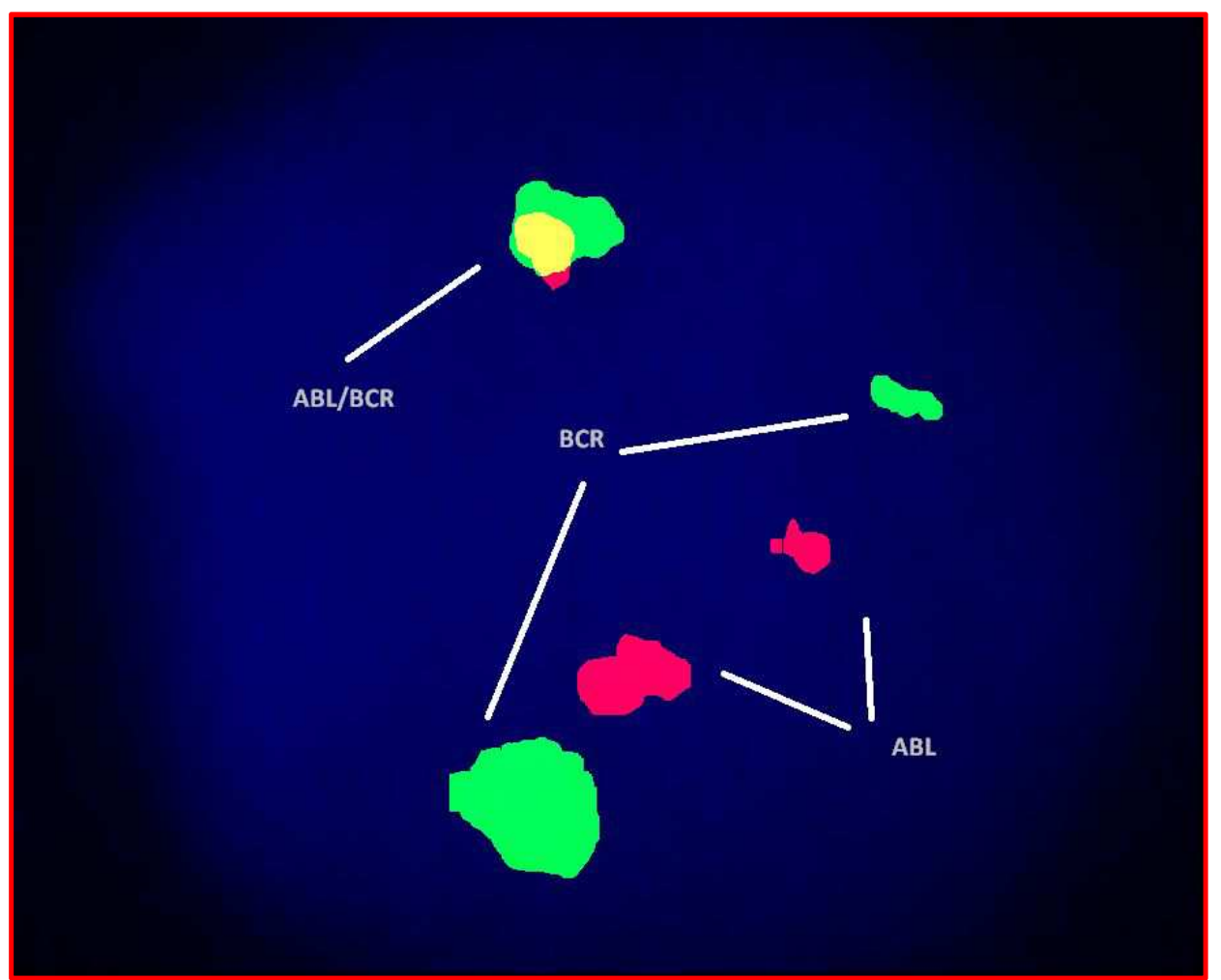

Figure 3. FISH Interphase Cell Showing 1 Fusion, 2 Green and 2 Orange Confirming Ph Positive Variant Chromosome Compliment. 
It is reported in the literature that different mechanisms involved in the formation of variant translocation may have different clinical implications. The clinical significance of variant $\mathrm{t}(9 ; 22)$ translocation is not clear but a study carried out by Albano et al.[20] have shown that the rearranged regions are characterized by an elevated content of miRNAs, Alu repeats, GC and known genes.

\section{References}

[1] Deininger MWN, Goldman JM, Melo JV. The molecular Biology of chronic myeloid leukemia. Blood 2000; 96: 33433356.

[2] Johanssan B, Fioretos T, Mitelman F. Cytogenetic and molecular genetic evolution of chronic myeloid leukemia. Acta Hematologica 2002; 107:76-94.

[3] Quintas-Cardama A, Crotes J. Molecular Biology of bcr-abl positive chronic myeloid leukemia, Blood 2009; 113(8): 16191630.

[4] Hicks GA, Dewad GW. Incidence and type of variant $\mathrm{Ph}$ chromosomes in 378 patients with a $\mathrm{Ph}$ chromosome. Karyogram 1995; 11: 105 - 109.

[5] Markovic VD, Bauman D, Bayani J, Al-Magharbi J, KamelReid S, Sauire JA. Lack of BCR/ABL reciprocal fusion in variant Philadelphia chromosome translocations; a use of double fusion signal FISH and spectral karyotyping. Leukemia 2000; 14: 1157-1160.

[6] Sawyers CL. Molecular consequences of the BCR-ABL translocation in chronic myeloid leukemia. Leukemia Lymphoma 1993; 22(2): 101-103.

[7] Mitelman F, Johansson B, Mertens F. Data base of chromosome aberrations in cancer. http://cgap.nci.nih.gov/chromosomes/Mitelman: 2001.

[8] Seabright M. A rapid banding technique for human chromosome. Lancet 1971; 2: 971-972.

[9] International System for Human Cytogenetic Nomenclature (ISCN). S. Karger Pub. Inc. 2009.

[10] Aliano S, Cirmena G, Fugazza G, Bruzzone R, Palermo C, Sessargo M. Standard and variantPhilaelphia translocation in a CML patients with different sensitivity to imatinib therapy. Leukemia Res. Report 2013; 2: 75-78.
[11] Hagemeijer A, Bartram CR, Smit EME, Van Agthoven AS, Boostama $\mathrm{D}$. Is the chromosome region $9 \mathrm{q} 34$ always involved in variant of the Ph1 Translocation?Can. Genet.Cytogent.1984; 13: $1-16$.

[12] Aventin A, Mecucci C, Louwagie A, Shutyers J, Van Den Berghe $\mathrm{H}$, Bandeo de altaresolucion en el analisiscitogenetico de la leucemiamioloide Cronica con translocacioncompleja. Sangre. 1987; 32: 6-11.

[13] Calabrese G, Stuppia L, Franchi PG, Pelia R, Martizio E, Liberati M, Spadano A, Di Loenzo R, Donti E, Antonucci A. Complex translocations of the $\mathrm{Ph}$ negative $\mathrm{CML}$ arise from similar mechanism as evidenced by FISH analysis Can. Genet.Cytogenet. 1994; 78(2): 153-159.

[14] Gudi R, Elizalde A, Gogeneni SK, Macera MJ, Badillo A, Verma RS Characterization of a complex translocation [t(4;9;22)(p16;q32;q11) ] inChronic myelogenousleukemia by fluorescence in situ hybridization technique.Can. Genet.Cytogenet.1996; 90: 142-145.

[15] Morel F, Herry A, Le Bris MI, Morice P, Bouguard P, Abgrall JF, Berthou C, De Braekekeer M. Contribution of fluorescence in situ hybridization analyses to the characterization of masked and complex Philadelphia chromosome translocation in CML. Can. Genet.Cytogenet. 2003; 147: 115-120.

[16] Gorush M, Benn P, Li Z, Fang M. On the genesis and prognosis of variant translocations in CML.Can. Genet.Cytogenet 2007; 173: 97 - 106.

[17] Reid AG, Huntly BJ, Grace C, Green AR, Nacheva EP. Survival implications of molecular heterogeneity in variant Philadelphia positive CML. Brit. J. Hematol 2003; 121: 419427.

[18] Socnen V, Viguic F, Lai JL, Andricux J, Corm S, RocheLestiennc C, Fi LMC. Group mechanisms of genesis of variant translocation in $\mathrm{CML}$ are not correlated with $\mathrm{ABL}$ or BCR deletion status or response to imatinib therapy. Can Genet. Cytogenet 2008; 182: 95 - 102.

[19] De Brackeleer M. variant Philadelphia translocations in CML. Cytogenet. Cell Genet 1987; 44: 215 - 222.

[20] Albano F, Anelli L, Zagaria A, Coccaro N, Casieri P, Russo Rossi A, et al. Non random distribution of genomic features in breakpoint regions involved in chronic myeloid leukemia cases with variant $\mathrm{t}(9 ; 22)$ or additional chromosomal rearrangements. Molecular cancer 2010; 9: 120. 